the patient'. Better that, perhaps, than our new idolatries, of making gods out of slogans.

G R DUNSTAN Department of Theology, The University of Exeter

\section{Ethical Issues in Preventive Medicine}

\author{
S Doxiadis, editor, 108 pages, \\ Dordrecht/Boston/Lancaster, $£ 33.25$, \\ Martinus Nijhoff Publishers, 1985
}

This book is a transcript of 16 working papers (with edited discussions) of an interdisciplinary workshop, sponsored by the NATO Scientific Council, and held in Athens in January 1985. The topics included confidentiality, informed consent, intervention trials, screening, resource allocation, occupational medicine, and the conflict between the individual and the State, between personal freedom and 'the common good'.

As the first book on the ethics of preventive medicine it should be welcome; it is about 30 years overdue. Still, it has all the shortcomings of a fledgling: it stumbles around, struggles with language, asks questions to which there are no answers. Regrettably, the book has no references and no suggestions for further reading.

Preventive medicine is nowhere defined and some issues discussed are scarcely 'medical', for example, crashhelmet and seat-belt legislation. Also it would stretch the term 'medicine' too much if it were to include the problems of 'improving individual behaviour', 'manipulation of behaviour by controlling the contingencies of reinforcement', and the whole gamut of stick-and-carrot methods used by the State to make the people abandon their erring ways.

The language of rights permeates the book. What does 'No one has a right to happiness but rather a right to the pursuit of happiness' mean? Is there a meaningful answer to the question: 'Has the individual the right to take a voluntary health risk'? The interrogator has mastered Newspeak. One participant even advocated the right of a sick fetus not to live (sic). Did not Jeremy Bentham once say that to talk about rights is nonsense and to talk about natural rights is nonsense upon stilts?

Many important problems surfaced at the workshop, such as the lack of evidence for the benefit of health promotion, which is taken for granted; the paradox that preventive measures may lead to an increase in the health budget and to medicalisation of the healthy; and the opportunity cost foregone in cancer screening programmes ( $\$ 300$ million was spent in the UK on cervical smears for a dubious benefit, while the money might have been spent more wisely on something else). Some platitudes got a hearing, too: 'An ounce of prevention is worth a pound of cure'. As $\mathrm{H}$ L Mencken observed, a platitude is a statement which a) everyone believes, and which b) is not true. Is not ten pence of prevention a day more expensive than a $£ 10$ cure a year?

Other important problems were left out, such as Rose's prevention paradox (how to persuade the population to participate in activities which may be good for society but which offer little benefit to participating individuals - if they were told the truth they would not bother); the metastasising healthpromotion industry searching for its raison d'être; and the ethics of the criminalisation of addictive behaviour. The two opposing ideologies in preventive medicine, corresponding to the open and closed societies of Popper, were not explicitly spelt out, although they were discernible in the discussions and ultimately this is what the book is about.

The disappointing input of theologians was hinted at by Professor Dunstan (himself a priest and an exception to his own rule): 'Modern Christianity seems to be trying to apply the brakes rather than to offer positive guidance for the future evolution of the use of new knowledge'.

One American speaker accused the British Government of suppressing a comissioned report on alcoholism, which had to be 'smuggled out of the UK and published in Sweden' (?!), presumably because it showed what everyone knew, viz' 'the government has an interest in the production, distribution and consumption of alcohol'. It did not occur to the speaker that so do the people who elected the government. The same speaker insisted on his right to be protected from the person who smokes. As a matter of symmetry, smokers and drinkers should have the right to be protected from such zealots. Understandably, this issue was not raised at the workshop.

PETR SKRABANEK Lecturer, Department of Community Health, Trinity College, Dublin
The End of Life: Euthanasia and Morality

James Rachels, 204 pages, Oxford, $£ 12.95$, paperback £3.95, Oxford University Press, 1986

For two reasons I found this book difficult to review. First, I became personally extremely involved, which reflects, of course, the interest generated by the author's arguments. However, I had to guard against the temptation of offering the readers of this journal my own views on the topic rather than my assessment of Professor Rachels's book.

Secondly, I am not a philosopher and, therefore, recognised my inability to make a scientific appraisal of the author's philosophical arguments. I also lack a thorough knowledge of the great philosophers whose theories are invoked.

It is claimed for the book, that it is 'for anyone who cares about the way we treat other human beings; ... . for anyone who has stopped to consider what we really mean by respect for human life'. Having spent some 40 years in the nursing profession, I feel justified in counting myself as such an 'anyone' and my review is, therefore, based on this, rather than on a philosophical, background.

In order to convey the approach to the topic adopted by the author, it is necessary to list the chapter headings. There are ten chapters, each of which is rich in information and food for deep thought: The Western tradition; The sanctity of life; Death and evil; 'Innocent humans'; Suicide and euthanasia; Debunking irrelevant distinctions; Active and passive euthanasia; Further reflections on killing and letting die; The morality of euthanasia; Legalising euthanasia.

In the first three chapters the author takes us through some of the major tenets of the great philosophers and traditions of thought, both in the Western and the Eastern cultures, showing the striking contrasts between them.

From the 17th century onwards, morality was no longer considered to require a religious foundation and was opened up to a wider debate. Professor Rachels rightly brings the debate into the end of the 20th century using the distinction between 'having a life' and 'merely being alive' as a springboard, a distinction which he illustrates with some telling case studies. 
The major part of the book, that is chapters 4 to 10 , deals with the main philosophical, religious, moral and political arguments supporting and rejecting euthanasia, all of which are freely discussed. I felt that the chapters could have been arranged in a more logical sequence but this does not detract from the fascination of the book.

Another feature of the book which is worthy of note, is the absence of references in the text; instead an appendix in the form of 'notes on sources' is provided. The author defends this method as being less intrusive in the body of the text. I think he has a point, although a final list of references would have been useful.

My main points of concern about the book are:

1. In support of euthanasia, there is frequent reference to 'the person in agony', in excruciating pain. In my view, which is backed up by experience, medical and nursing care can now offer effective control of pain. Pain, therefore, cannot be regarded as a reason for euthanasia, but should rather be seen as a challenge to the health professions.

2. The other frequently quoted example in support of euthanasia is the baby with severe congenital defects and abnormalities. Of course, intuition and reason suggest that death would be preferable to permanent dependence, which places excessive burdens on carers. To my own surprise, my experience suggests that many parents and other carers have felt enriched by the sacrificial care they gave.

3. Accepting the profound difference between 'having a life' and 'being alive', Professor Rachels has not convinced me that he, or anyone else, can judge the 'life' experience of another: an experience is, by definition, personal and unique to the person having it.

4. The 'slippery slope' argument, often produced in opposition to euthanasia, and exemplified by the Nazi atrocities, is discussed by the author, who dismisses it as a relevant analogy on the grounds that the term 'euthanasia' is misused in such an argument. Having come uncomfortably close to that situation, I do not feel able to agree with him. It was a prominent part of the Nazi ideology that the 'impure', such as the misshapen and the pain-tortured, could not 'have a life': they were inadequate for modern society and, on utilitarian grounds, greater happiness for all would be achieved by their extermination.

5. In his final chapter, Professor Rachels makes a case for legalising euthanasia. This, he suggests, could be done quite 'simply' by accepting a plea of mercy-killing as a defence against a charge of homicide, in much the same way as a plea of self-defence is acceptable. He relates examples of judges' leniency in cases of 'mercy killing' where the accused has been put on probation rather than committed to prison. However, not only is a period of probation an indisputable form of punishment: he himself agrees that courts are not always so lenient. In my view, it would be dangerous, to say the least, to leave a verdict on such a delicate issue to the whims of judges who, unfortunately, are not beyond human failure or even corruption.

In conclusion, this is a book in which the complex and highly relevant topic of euthanasia and morality has been fairly and sensitively treated and which deserves to be read, studied and widely discussed. It is controversial, stimulating and instructive and I commend it warmly to all who are concerned with and about living, dying and having life.

\section{formerly Director, Nursing Studies Research Unit, University of Edinburgh}

\section{The Foundations of Bioethics}

H Tristram Engelhardt Jr, 398 pages, New York, $£ 24.00$, US $\$ 27.95$, Oxford University Press, 1986

The Foundation of Bioethics is presented as the first full-scale treatment of the subject by a single author. Engelhardt, a professor of both medicine and philosophy, and the editor of the Fournal of Medicine and Philosophy is well placed to provide it. His book has inevitably attracted much advance attention from prominent figures in the field. One of them, James Childress, describes it as 'a philosophical justification for a secular pluralist morality based on the limits of authority and reason', although the author himself stresses that his initial intent was rather the opposite. In trying, and failing, to justify a particular view of the good life by reason alone, Engelhardt came to see 'with dismay and sorrow' the inevitability of secular pluralism. He clearly regrets the resultant intellectual untidiness, but proceeds to examine with gusto its implications for the practice of medicine and health care policy.
The author traces the origins of $\frac{\mathbb{D}}{\mathrm{D}}$ pluralism back to the break-up of the 2 Christian consensus, beginning with Luther, and the scientific revolution, beginning with Copernicus. He then follows it forward to the brink of nihilism, from which we are rescued by a morality based on the recognition by reason of two fundamental (and at times conflicting) principles, namely the utilitarian requirement of beneficence, and the Kantian requirement of respect for autonomy. The proper application of these leads to the building of what the author calls 'the peaceable community', from whose features he goes on to derive an account of what it is to be a person: namely, a self-conscious rational moral agent possessed of autonomy.

Using this central concept of person, Engelhardt pursues a variety of avenues to a wide range of practical conclusions, which are often controversial. He ف่ would, for example, permit liberalised 음 abortion, some fetal experimentation, limited infanticide of defective newborn babies, euthanasia, and the declaration as dead of those lacking higher braincentre functions. In addition, he spends a chapter each on the requirement for informed consent, the rights to healt $B$ care, and the nature of nosology, $\mathbb{Q}$ from the same perspective Throughout, the text is extensive annotated, with well-selected but not exhaustive references, and a good index.

Such a unifying enterprise as this stands or falls with its central premisses: and for Engelhardt they are essentially political. He has an ideal, the peaceable community, in which many groups of different religious and political leanings co-exist by virtue of common acknowledgement of the limits, set by reason, to the force they can use on others of different persuasions. This is all very well: but the weak point in Engelhardt's treatise is to argue from such a political notion to the nature of persons, rather than vice versa. If personhood is so crucial to the settling of issues of practical policy, it is difficult $\sigma$ to accept that it is at the same time $N$ derivative of a conception of the ideal political community.

Whether it is more appropriate to argue from the nature of man to the nature of his community or the reverse $\frac{}{D}$ is an old dispute. What is new in ? Engelhardt's book is the attempt to 7 relate, at its root, political philosophy to ${ }_{\vec{C}}$ practical issues in medical ethics. As $\stackrel{\mathbb{D}}{\Omega}$ such, it is an ambitious and admirable $\frac{}{\mathbb{D}}$ effort, comprehensive in scope and $\varrho$ challenging in content. In the words of another prominent commentator, 